Carsley, Effectiveness of mindfulness-based colouring for test anxiety in adolescents, 'School Psychology

International' $(39,3)$ pp. 251-272. Copyright @ 2018 . DOI: $10.1177 / 0143034318773523$.

\title{
Effectiveness of mindfulness-based colouring for test anxiety in adolescents
}

\author{
Abstract \\ The purpose of this study was to compare the effectiveness of a mindfulness art activity \\ (mandala) with a free draw/colouring activity on test anxiety in adolescents with an examination \\ of gender differences, and to assess the effect of dispositional mindfulness on students' \\ experience of mindfulness and test anxiety states. Participants were 193 Grade 8 students (56.6\% \\ female; $M_{\text {age }} 13.49$ years, $\left.S D=0.50\right)$ randomly assigned to a mandala $(n=97)$ or free \\ draw/colouring condition $(n=96)$. Students completed standardized measures to assess test \\ anxiety and state mindfulness pre- post-colouring intervention, immediately prior to completing \\ a test, in addition to a measure of dis- positional mindfulness. Results showed a significant \\ decrease in test anxiety and a significant increase in state mindfulness following both activities; \\ however, a gender by group by time interaction was found such that females reported a greater \\ decrease in test anxiety in the free condition compared to males. Furthermore, the baseline \\ measures (pre-intervention state mindfulness and test anxiety) were found to fully mediate \\ relations between dispositional mindfulness and the outcome measures (post-intervention state \\ mindfulness and test anxiety). Implications for educators and future research and practice \\ regarding the use of mindfulness activities in the classroom are discussed.
}

\section{Keywords}

adolescents, art making, mandala, mindfulness, test anxiety

Mindfulness-based programs have become increasingly popular school-based interventions for youth (Tan, 2016; Zenner, Herrnleben-Kurz, \& Walach, 2015; Zoogman, Goldberg, Hoyt, \& Miller, 2014). Mindfulness involves the ability to pay attention to the moment, on purpose, without judgement (Kabat-Zinn, 2003) and can be regarded as a state or 
disposition; specifically, individuals can experience moments of mindfulness (state mindfulness) and/or maintain a general ability to be mindful (dispositional mindfulness). Mindfulness-based interventions have been incorporated in schools for anxiety reduction, and recently, studies have examined the effectiveness of mindfulness-based approaches to help elementary (age 9- to 12years-old) and secondary school students (age 13- to 15-years-old) manage anxiety in test situations (e.g., Arjunan \& Joseph, 2016; Carsley, Heath, \& Fajnerova, 2015; Napoli, Krech, \& Holley, 2005). Despite these emerging studies, there is limited research on the effectiveness of feasible mindfulness-based approaches for test anxiety in adolescence, when test anxiety is a growing problem that needs to be addressed (von der Embse \& Hasson, 2012).

Mindfulness-based art making has received attention in the literature and popular culture as a feasible activity for test anxiety, anxiety, and stress reduction (Carsley et al., 2015; Carsley \& Heath, 2018; Curry \& Kasser, 2005). Colouring structured mandalas (circles composed of small symmetrical shapes) has been incorporated in schools, as colouring in these shapes is believed to encourage focused attention and awareness of current experiences (Beckwith, 2014). Recently, studies have examined the effectiveness of structured mandala colouring for test anxiety in children compared to free colouring (Carsley et al., 2015; Carsley \& Heath, 2018); however, results from these studies have shown that (1) it is unclear whether the suggested mindfulness strategy of colouring mandalas is the most beneficial colouring technique for decreasing test anxiety, and (2) individual differences may help explain students' responses to this activity. The purpose of this study is to examine the effectiveness of mindfulness-based colouring for test anxiety in adolescents, and individual factors that may explain students' receptivity to this activity.

Test anxiety, an individual's response to test-taking, is a concern among adolescents as 
Carsley, Effectiveness of mindfulness-based colouring for test anxiety in adolescents, 'School Psychology International' $(39,3)$ pp. 251-272. Copyright @ 2018 . DOI: 10.1177/0143034318773523.

testing requirements are increasing and students feel pressured to succeed academically (Lowe, Grumbein, \& Raad, 2011; Wren \& Benson, 2004). One-third of adolescents report experiences of test anxiety (Lowe \& Lee, 2008; Whitaker-Sena, Lowe, \& Lee, 2007), which includes test anxiety states (immediate concerns before a test) or individual traits (day-to-day concerns associated with testing situations; Lowe \& Lee, 2008). Adolescents report that their greatest school-based worries and anxieties include test-taking and assessment (Putwain, Chamberlain, Daly, \& Sadreddini, 2014), and unlike other fears, test anxiety increases with age as youth progress through school (McDonald, 2001; Peleg, 2004).

Individuals reporting test anxiety may also experience other types of anxiety disorders (King, Mietz, Tinney, \& Ollendick, 1995; LeBeau et al., 2010), low self-esteem (Pekrun, 2000), lower academic performance, grades, standardized achievement scores (Eum \& Rice, 2011; Everson, Millsap, \& Rodriguez, 1991; Segool, Carlson, Goforth, Von der Embse, \& Barterian, 2013), challenges with learning new material (Chapell et al., 2005), lack of motivation, negative self-evaluation, struggles with concentration (Swanson \& Howell, 1996), grade retention (Hembree, 1988), and dropout (Chapell et al., 2005; Tobias, 1979). Many test anxiety interventions for youth are time-consuming, (e.g., Bradley et al., 2010; Gregor, 2005; Larson et al., 2010; Weems et al., 2009; Yahav \& Cohen, 2008), and continuous implementation of these programs poses a challenge for educators due to existing curriculum demands. Given that adolescents report tests as a critical source for worry throughout their school experience (Putwain et al., 2014) and that there are many challenges associated with test anxiety, there is a need for feasible and effective test anxiety interventions.

Mindfulness has been shown to be a practical and feasible school-based intervention for youth (Carsley, Khoury, \& Heath, 2017). Originating from Eastern perspectives, mindfulness 
consists of a comprehensive awareness and alertness on the present moment (Bodhi, 2011; Dalai Lama \& Berzin). Throughout the last 20 years, this construct has become prevalent in Western cultures as a way of focusing attention and developing awareness of the moment (Miller, Fletcher, \& Kabat- Zinn, 1995). Specifically, mindfulness is considered to be a theoretical construct, a practice, and a psychological state (Germer, 2005). In addition to the goal of being mindful, mindfulness includes a practical element, in which individuals participate in practices to experience focused attention and present-moment awareness (Kabat-Zinn, 2003).

Mindfulness-based interventions have been incorporated in high schools for general anxiety (Beauchemin, Hutchins, \& Patterson, 2008; Burke, 2010; Zenner et al., 2015), and test anxiety reduction (Arjunan \& Joseph, 2016). In a recent meta-analysis (Kallapiran, Kirubakaran, \& Hancock, 2015), mindfulness- based interventions were associated with reduced anxiety, among other mental health concerns (e.g., depression, stress) in children and adolescents. Zoogman and colleagues' (2014) meta-analysis on mindfulness interventions for youth demonstrated significantly greater effect sizes for mindfulness interventions targeting psychological symptoms compared to physiological and cognitive outcomes. Mindfulness has been associated with a multitude of well-being benefits for adolescents (e.g., reduced anxiety, test anxiety, stress), and the Developmental Contemplative Science (DCS; Roeser \& Pinela, 2014) theory can help explain how mindfulness functions in this population. DCS, part of the Social- Emotional Learning (SEL) field, focuses on the mechanisms by which individuals use knowledge, attitudes, and skills for understanding and managing emotions, set and accomplish positive goals, demonstrate empathy for others, create and sustain positive relationships, and make sensible choices (CASEL, 2015). A focus of SEL, DCS is concerned with understanding the mind-body system for use in a curriculum of mental training in education (i.e., mindfulness) 
to enhance human development within and across developmental periods (e.g., Frank, Jennings, \& Greenberg, 2013; Roeser, 2013; Roeser \& Pinela, 2014; Roeser \& Zelazo, 2012).

Drawing on previous research, DCS proposes three core premises for the mechanisms by which mindfulness functions. First, it has been suggested that the brain adapts in response to experience, intentional training and/or education (e.g., mindfulness activities); neuroplasticity leads to actual physiological changes. Second, engaging in mindfulness activities will eventually lead to increases in mindfulness; secularized mindfulness training (i.e. skill acquisition and eventual development of expertise) can significantly alter day-to-day cognitive and emotional processes. Finally, there are specific developmental periods in which particular brain regions and networks are more likely to be modified, and developmental stages (e.g., early adolescence) can predispose an individual to be open to training. This theory suggests that response to mindfulness training differs between developmental periods (Roeser \& Pinela, 2014; Roeser \& Zelazo, 2012) and adolescents in early high school represent a developmental period in which mindfulness activities can be particularly beneficial.

Mindfulness-based activities have been incorporated in educational settings for adolescents (Carsley et al., 2017); however, school demands limit the feasibility of continuing to implement these programs within schools. Many existing mindfulness-based school programs require several sessions integrated into the school schedule over multiple weeks (e.g., Britton, Lepp, Niles, Rocha, Fisher, \& Gold, 2014; Johnson, Burke, Brinkman, \& Wade, 2016). These programs include activities such as breath counting and awareness exercises, guided-mindfulness audio files, body scans and sweeps, and can be incorporated in the classroom once a week for 35-60 minutes over a number of weeks, or for shorter periods several times a week. These programs have been found to be effective in reducing anxiety in youth (e.g., Bennet \& Dorjee, 
2016; Britton et al., 2014; Kallapiran et al., 2015; Zoogman et al., 2014); however, the time commitment and participation from the teachers in consistently implementing these activities in their classrooms poses a significant challenge as school-based programs requiring a lot of time are difficult to implement and are not likely to be carried out over time (Bishop, Bryant, Giles, Hansen, \& Dusenbury, 2006; Fridrici \& Lohaus, 2009). Research has found that single-session 15-minute mindfulness meditations have been effective in reducing negative affect (Arch \& Craske, 2006; Hafenbrack, Kinias, \& Barsade, 2014) and negativity bias (Kiken \& Shook, 2011); as such, it would be beneficial to assess brief and effective mindfulness interventions for teachers to incorporate in their classrooms, and that students could easily use to diminish anxiety resulting from test-taking.

Recently, there has been an increase in studies examining the effectiveness of brief mindfulness-based art activities for test anxiety and anxiety reduction in elementary and college samples (Carsley et al., 2015; Carsley \& Heath, 2018; Curry \& Kasser, 2005; Van der Vennet \& Serice, 2012). Structured mandala colouring is considered to be mindfulness-based as colouring in the detailed shapes is believed to allow individuals to experience focused awareness of the present moment, as they develop a mindfulness state (Beckwith, 2014; Carsley et al., 2015; Curry \& Kasser, 2005; Henderson, Rosen, \& Mascaro, 2007). This intervention has been shown to be effective for reducing anxiety and test anxiety in students, and feasible for implementation in schools, as unlike other mindfulness-based programs, it requires limited resources, teacher demands, and training (Carsley et al., 2015; Carsley \& Heath, 2018; Curry \& Kasser, 2005; Van der Vennet \& Serice, 2012). Colouring in the intricate shapes and patterns allows students to experience a focused and aware state inherent to mindfulness, which has also been found in other forms of meditation (Curry \& Kasser, 2005). The frontal lobes of the brain, which are essential 
for executive functions such as planning and organizing, are potentially one of the last areas of the brain to develop and may not even develop until later in life (Sowell, Thomson, Holmes, Jernigan, \& Toga, 1999); therefore, engaging in mandala colouring, which includes a planned structured design, can help adolescents organize their experience as they are provided with a sense of direction to guide their organization, unlike free colouring. The lack of structure found in free colouring can be challenging and stressful, and has been suggested to induce anxiety in students, as they feel required to create their own structure (Curry \& Kasser, 2005), particularly if their executive functions are not fully developed. Although colouring mandalas has been found to be effective in reducing anxiety compared to unstructured colouring in university students (Curry \& Kasser, 2005; Van der Vennet \& Serice, 2012), several studies conducted with elementary school students have demonstrated that free colouring can be as effective as mandalas for decreasing test anxiety, as well as increasing mindfulness states (Carsley et al., 2015; Carsley \& Heath, 2018).

In Curry and Kasser's (2005) and Van der Vennet \& Serice's (2012) studies, university students participated in structured mandala, unstructured free, or structured plaid form colouring for 20 minutes following an anxiety induction. Anxiety was assessed using the State-Trait Anxiety Inventory at baseline, pre-colouring, and post-colouring activity. Participants in Curry and Kasser's study ( $N=84 ; 65 \%$ female) demonstrated significantly greater decreases in anxiety in the mandala and structured plaid form groups compared to the free group. In Van der Vennet and Serice's replication study $(N=50 ; 82 \%$ female), students in the mandala condition reported greater decreases in anxiety compared to the free condition; however, participants in the free condition also demonstrated decreases in anxiety; as such, further examination of these activities was required. 
In the first study examining the effectiveness of structured mandala versus free unstructured colouring for test anxiety in children, both activities were found to be effective in reducing test anxiety (Carsley et al., 2015). Participants were 52 students in grades 4 to 6 (53.8\% female), randomly assigned to one of two colouring activities, which were completed before a spelling test. Although significant overall decreases in test anxiety for both groups were found, males reported significantly greater decreases in test anxiety in the free condition, compared to females $\left(\eta_{p}^{2}=0.058\right)$. According to Carsley et al. (2015), these differing responses could possibly be due to inherent gender differences between males and females in response to mindfulness activities. It is also possible that males' fine motor skill development occurs later than females, which would explain their significant decreases in test anxiety following the free activity, unlike females. These findings may also suggest underlying individual differences in dispositional mindfulness, which might influence students' ability to respond mindfully to mindfulness-based interventions.

To further examine the underlying factors contributing to this gender difference, Carsley and Heath (2018) assessed the effectiveness of these colouring activities on test anxiety and state mindfulness with children in grades 4 to $6(N=152 ; 50 \%$ female $)$, randomly assigned to a structured mandala or a free draw/colouring group, matched for gender. Students completed the State-Trait Anxiety Inventory for Children-State form and an adapted version of the Mindful Attention Awareness Scale, state version, before and after colouring. Participants then completed a spelling test and the Child and Adolescent Mindfulness Measure to assess dispositional mindfulness. Consistent with Carsley et al. (2015), results revealed overall significant decreases in test anxiety $\left(\eta^{2}=0.178\right)$, and significant increases in state mindfulness pre-post-intervention $\left(\eta^{2}=0.084\right)$ for both groups; however, there were no gender differences. 
Carsley, Effectiveness of mindfulness-based colouring for test anxiety in adolescents, 'School Psychology International' $(39,3)$ pp. 251-272. Copyright @ 2018 . DOI: 10.1177/0143034318773523.

In addition, Carsley and Heath (2018) found a significant positive correlation between dispositional mindfulness and pre-intervention state mindfulness; however, there was a ceiling effect such that children with higher dispositional mindfulness also indicated high reports of state mindfulness pre-intervention, demonstrating there was little room for them to improve in their mindfulness post-intervention. Dispositional mindfulness has been shown to contribute to psychological well-being outcomes from mindfulness interventions, including test anxiety (Cunha \& Paiva, 2012; Napoli et al., 2005), can develop over time, and is associated with the experiencing of state mindfulness following an intervention (Kiken, Garland, Bluth, Palsson, \& Gaylord, 2015; Shapiro, Oman, Thoresen, Plante, \& Flinders, 2008). Carsley and Heath's (2018) study revealed that individuals with higher dispositional mindfulness already report high statemindfulness pre-intervention and may not experience the mindfulness benefits compared to those with lower dispositional mindfulness. Although significant increases in mindfulness states were found following the colouring activities, this change was found for participants who reported lower pre-intervention state mindfulness and dispositional mindfulness; therefore, it appears as if dispositional mindfulness is influencing pre-intervention state mindfulness, which in turn is determining whether participants are able to report benefits/changes post-intervention. It would be important to examine the effect of dispositional mindfulness on adolescents' post-intervention state mindfulness through their pre-intervention reports, as well as the effect of dispositional mindfulness on post-intervention test anxiety through reports of pre-intervention test anxiety, to determine whether this individual difference can impact students' response to the intervention. The results from the elementary studies provide additional information on the effectiveness of these art activities and preliminary explanations for the contribution of dispositional mindfulness for a mindfulness intervention. Given that (1) adolescence is a period in which test anxiety is 
highly prevalent, (2) response to mindfulness training may be particularly beneficial for adolescents, (3) there is a need for brief and feasible test anxiety and mindfulness-based interventions in high schools, and (4) the role of dispositional mindfulness on participants' response to the intervention through their pre-intervention reports requires further examination, it is critical to examine the effectiveness of these activities with adolescents, as well as the individual differences (e.g., mindfulness dispositions, gender) that might impact response to the activity.

Mindfulness-based art making for anxiety and/or test anxiety has been studied in elementary and university populations; yet, there have been no studies conducted that assess the effectiveness of this activity in adolescence, a developmental period in which test anxiety is prevalent and mindfulness activities are theorized to be particularly helpful. The previously conducted elementary studies found that mandalas and free/draw colouring were associated with reductions in test anxiety pre-post intervention (Carsley et al., 2015; Carsley \& Heath, 2018); however, the university studies revealed that mandala colouring is more beneficial than free colouring at this age (Curry \& Kasser, 2005; Van der Vennet \& Serice, 2012). Based on the DCS theory that early adolescence represents a developmental period in which students will experience mindfulness benefits associated with a mindfulness-based activity, and that the potential benefits of mindfulness-based art making for adolescents has yet to be investigated, the purpose of this study was to address this gap and expand on the previously conducted studies by examining the effectiveness of a mindfulness-based art activity for test anxiety in high school students. Given the differences in executive functioning throughout development (Sowell et al., 1999), one might expect differential findings with mindfulness-based art compared to free colouring during adolescence. This research will help advance the previously conducted research 
Carsley, Effectiveness of mindfulness-based colouring for test anxiety in adolescents, 'School Psychology International' $(39,3)$ pp. 251-272. Copyright $\odot$ 2018. DOI: 10.1177/0143034318773523.

in this area and elucidate possible developmental differential responses to this intervention in adolescents. The first objective is to compare the effectiveness of a structured mindfulness colouring (mandala) with a control free/draw colouring activity on reducing test anxiety and increasing state mindfulness in adolescents prior to a test, with an examination of possible gender differences. We hypothesize that students in the mandala condition will report greater decreases in test anxiety (H1) and greater increases in state mindfulness (H2) compared to participants in the free condition. Based on the mixed gender findings in previous literature, the absences of reported gender differences in adolescence, and because there is no identifiable mechanism as to why such a difference might occur, no directional hypotheses regarding gender are proposed. The second objective is to assess the effect of dispositional mindfulness on students' mindfulness and test anxiety states post-intervention. Drawing on the literature that showed a relation between dispositional mindfulness and pre-intervention state mindfulness (Carsley \& Heath, 2018), and the likelihood that dispositional mindfulness influences preintervention state mindfulness, which in turn is determining participants' ability to report benefits post-intervention, we hypothesize that pre-intervention state mindfulness would mediate relations between dispositional mindfulness and post-intervention state mindfulness (H3), and that pre-intervention test anxiety would mediate the relation between dispositional mindfulness and post-intervention test anxiety $(\mathrm{H} 4)$.

\section{Methods}

\section{Participants}

Participants were 193 Grade 8 students ( $56.6 \%$ female; $M_{\text {age }}=13.49$ years, $S D=0.50$ ) from public co-ed elementary schools in Montreal, Quebec, Canada. These particular schools have rigorous entrance requirements, thus this study included a sample of high achieving 
students. Once university ethics, school board and governing board approvals were obtained, an oral script describing the study was read and consent forms were provided to the students to take home to their parents. Students agreeing to participate returned the forms. Of the 265 consent forms distributed, 195 approved consent forms were received (74\% consent); two students were not able to participate due to absence. The final sample included 193 participants. Random assignment revealed that the groups did not differ according to gender (mandala: $n=97 ; 54.6 \%$ female; free: $n=96 ; 58.3 \%$ female).

\section{Measures}

\section{State-Trait Anxiety Inventory-State Anxiety Scale.}

The State Anxiety Scale from the State-Trait Anxiety Inventory (STAI) is a widely used self-report measure assessing adolescents', college students', and adults' current state of anxiety (Spielberger, 1989). The state scale contains 20 items for individuals to indicate how they feel in a particular moment in time and takes 5-10 minutes to complete. Items include statements such as 'I am worried' or 'I feel upset' and participants indicate their response on a four-point scale $(0=$ not at all $; 4=$ very much so $)$. This measure has been shown to have high internal consistency $(\alpha=0.86-0.96)$ and test-retest reliability ranging from 0.65 to 0.76 (Spielberger, Gorsuch, Lushene, Vagg, \& Jacobs, 1983). In the present study, Cronbach alphas ranged from 0.88 to 0.90 pre-post-intervention, with a test-retest correlation of 0.65 .

\section{Mindful Attention Awareness Scale, state version.}

The Mindful Attention Awareness Scale, state version (state MAAS) measures current mindfulness states, and is based on the original Mindful Attention Awareness Scale, which measures trait mindfulness (Brown \& Ryan, 2003). The state MAAS includes five items modified from the original MAAS. The state MAAS contains items directed toward a previous 
Carsley, Effectiveness of mindfulness-based colouring for test anxiety in adolescents, 'School Psychology

International' $(39,3)$ pp. 251-272. Copyright @ 2018 . DOI: $10.1177 / 0143034318773523$.

state-mindfulness experience (e.g., 'I was rushing through something without being really attentive to it'). For this study, items were adapted to measure immediate mindfulness experiences pre-post-intervention (e.g., 'Right now, I am rushing through this without really paying attention to it'). Participants report how they feel in a particular moment in time with a six-point scale $(0=$ not at all; $6=$ very $m u c h)$. Scores for this measure are reversed, such that lower scores demonstrate lower state mindfulness. In the current study, Cronbach alphas ranged from 0.74 to 0.84 pre-post-intervention, with a test-retest correlation of 0.74 .

\section{Child and Adolescent Mindfulness Measure.}

The Child and Adolescent Mindfulness Measure (CAMM) is a ten-item reverse-scored self-report measure of dispositional mindfulness for children and adolescents (Greco, Baer, \& Smith, 2011). Items on this measure include present moment awareness (e.g., 'I keep myself busy so I don't notice my thoughts or feelings') and non-judgmental acceptance (e.g., 'I stop myself from having feelings that I don't like'). Using a five-point scale ( $0=$ never true; $4=$ always true), participants report how often an item is true for them. In the present study, the CAMM was shown to have a Cronbach alpha of 0.84 .

\section{Procedure}

The researcher and assistants arrived at the schools and entered the students' classrooms to conduct the study. Students were randomly assigned to an intervention (mandala) or control (free) group. The researcher and assistants pro- vided all students with blank envelopes that included the questionnaires and either a structured mandala or blank sheet of paper for the colouring activities. The papers in the envelopes were only visible and opened by students once the study began to ensure the distribution procedure was completely random. Students were informed that their parents would receive their spelling test results upon completion of the study. 
This method of eliciting test anxiety is an effective method that has been used in previous studies (Carsley et al., 2015; Carsley \& Heath, 2018).

Students completed the STAI and the state MAAS. To ensure all instructions and items were clear, the researcher read through each item on the measures, and students were instructed to respond to each item truthfully. Following completion of the pre-intervention measures, students were provided with coloured pencils and the intervention group coloured in the same structured mandalas while the control group was asked to free draw/colour on a blank sheet of paper for 15 minutes. All participants then completed the STAI and state MAAS to evaluate post-intervention test anxiety and state mindfulness. To ensure consistency in the measures at the different time points, the researcher read through the questionnaires with the students.

All students then completed the spelling section of the Wide Range Achievement Test (WRAT4) over a 15-minute period. To assess dispositional mindfulness, students filled out the CAMM. Participants were then provided with a debriefing on the purpose of the study and the opportunity to ask questions. They received a debriefing sheet to take home to their parents, and a $\$ 10$ gift card to a local coffee shop. Once the data was entered, schools were given summarized group scores for the spelling test and test anxiety questionnaires. Each student's spelling and test anxiety scores were summarized and given to their parents, as well as resources for literacy and writing development, and anxiety management.

\section{Results}

Data were analysed with SPSS version 20. A total of ten missing values were found. Examination of missing data revealed that all variables had less than $5 \%$ of missing values. The Estimation Maximization (EM) procedure was conducted to impute missing data so that the sample size was maintained within each group. Nine univariate outliers were identified and 
transformed to values that were 1-unit lower or higher than the next lowest or higher value that was not an identified outlier (Tabachnick \& Fidell, 2007).

All relevant assumptions were checked and verified. As demonstrated in Table 1, the mandala and free group were not significantly different according to gender, age, and preintervention test anxiety and state mindfulness scores; therefore, these variables were not controlled for in all further analyses.

To test the effect of the colouring activities and gender on post-intervention test anxiety and state mindfulness, two separate repeated measures ANOVAs were conducted. Results for the repeated measures ANOVA for state mindfulness showed a significant main effect for time, $F(1$, $189)=42.26, p<0.01$, Wilk's $\Lambda=0.817$, partial $\eta^{2}=0.183$; examination of the means revealed that state mindfulness scores increased pre- to post-intervention for all conditions, regardless of gender (see Table 2). Results for the test anxiety analysis also showed a significant main effect for time, $F(1,189)=91.88, p<0.01$, Wilk's $\Lambda=0.673$, partial $\eta^{2}=0.327$; however, significant interactions were found between time and gender, $F(1,189)=6.58, p=0.011$, Wilk's $\Lambda=0.966$, partial $\eta^{2}=0.034$, and time, colouring activity, and gender, $F(1,189)=8.81, p=0.003$, Wilk's $\Lambda=0.955$, partial $\eta^{2}=0.045$. Students in the mandala condition reported significant decreases in test anxiety pre- post-intervention; however, females in the free condition reported significantly greater decreases in test anxiety compared to males in the free condition (see Figure 1.1 and 1.2).

To assess the role of pre-intervention state mindfulness in the relation between dispositional mindfulness and post-intervention state mindfulness, Preacher and Hayes' (2004) procedure was used to perform the mediation analysis. The effect of dispositional mindfulness on pre-intervention state mindfulness was significantly positive (path $a ; b=0.060, p<0.001$, CI[0.040, 0.081]); higher levels of dispositional mindfulness were associated with higher levels 
of pre-intervention state mindfulness. Similarly, the effect of pre-intervention state mindfulness on post-intervention state mindfulness was significantly positive (path $b ; b=0.752, p<0.001$, $\mathrm{CI}[0.647,0.858])$. The total effect of dispositional mindfulness on post-intervention state mindfulness was significant (path $c ; b=0.046, p<0.001, \mathrm{CI}[0.024,0.067]$ ). When controlling for pre-intervention state mindfulness, the direct effect of dispositional mindfulness on postintervention state mindfulness was not significant (path c'; $b=0.001, p=0.955, \mathrm{CI}[-0.016$, 0.017). Additionally, the indirect effect of dispositional mindfulness on post-intervention state mindfulness through pre-intervention state mindfulness was significant $(a b=0.045, \mathrm{CI}[0.027$, 0.065). These results show that pre-intervention state mindfulness fully mediates the relationship between dispositional mindfulness and post-intervention state mindfulness (see Table 3 and Figure 2.1).

Preacher and Hayes' (2004) procedure was also used to perform the mediation analysis assessing the role of pre-intervention test anxiety in mediating the relation between dispositional mindfulness and post-intervention test anxiety. The effect of dispositional mindfulness on preintervention test anxiety was significantly negative (path $a ; \mathrm{b}=-0.710, p<0.001, \mathrm{CI}[-0.884$, $-0.536])$; higher levels of dispositional mindfulness were associated with lower levels of preintervention test anxiety. The effect of pre-intervention test anxiety on post-intervention test anxiety was significantly positive (path $\mathrm{b} ; \mathrm{b}=0.508, p<0.001, \mathrm{CI}[0.404,0.612]$ ). The total effect of dispositional mindfulness on post-intervention test anxiety was significant (path $c ; \mathrm{b}=-0.459, p<0.001, \mathrm{CI}[-0.618,-0.305])$. When controlling for pre-intervention test anxiety, the direct effect of dispositional mindfulness on post-intervention test anxiety was not significant (path $\left.c^{\prime} ; b=-0.098, p=0.189, \mathrm{CI}[-0.245,0.049]\right)$. In addition, the indirect effect of dispositional mindfulness on post-intervention test anxiety through pre-intervention test anxiety 
Carsley, Effectiveness of mindfulness-based colouring for test anxiety in adolescents, 'School Psychology

International' $(39,3)$ pp. 251-272. Copyright @ 2018 . DOI: 10.1177/0143034318773523.

was significant $(a b=-0.361, \mathrm{CI}[-0.487,-0.258]$; therefore, there is evidence that preintervention test anxiety fully mediates the relationship between dispositional mindfulness and post-intervention test anxiety (see Table 4 and Figure 2.2).

\section{Discussion}

The purpose of this study was to assess the effectiveness of mindfulness-based art for test anxiety in adolescents. Specific objectives were to evaluate the effective- ness of structured mandala colouring compared to free colouring for test anxiety and state mindfulness in adolescents prior to a test, and to assess the role of students' pre-intervention mindfulness states and test anxiety in mediating rela- tions between dispositional mindfulness and post-intervention state mindfulness and test anxiety.

Consistent with the elementary studies (Carsley et al., 2015; Carsley \& Heath, 2018), participants in both conditions revealed significant decreases in test anxiety pre-postintervention, and significant increases in state mindfulness. These results demonstrate that both activities are equally effective for test anxiety reduction and further support findings from previously conducted elementary studies that both activities can be considered as mindfulnessbased art.

Although colouring structured mandalas has typically been defined as mindfulness-based colouring activities for anxiety reduction and promoted as such throughout popular culture, free draw/colouring may also be considered as mindfulness-based or include mindfulness components, as youth are reporting increases in state mindfulness following completion of both activities. These findings are important for educators looking to reduce test anxiety in their classrooms through mindfulness-based approaches, as a variety of simple colouring activities can be potentially beneficial, and not solely the suggested mandala strategy. 
Although both genders benefitted in terms of test anxiety reduction from the mandala condition, females in the free condition reported greater decreases in test anxiety compared to males in the free condition. These findings differ from the first elementary study (Carsley et al., 2015), which found that males experienced greater test anxiety reduction in the free condition while females only benefitted from the mandala condition. A number of possible explanations might account for these unexpected gender differences.

Throughout childhood, males experience slower development of fine motor skills compared to females, which may make colouring structured mandalas more challenging for males than free colouring; thus, males benefit more from free colouring than the mandala (Hanlon, Thatcher, \& Cline, 2000; Kail, \& Cavanaugh, 2015). During middle childhood, females' fine motor skills are gener- ally more developed than males and they are likely able to colour in the mandala's small shapes with greater ease than males, making the mandala effective for them at this age. In adolescence, females may have reached a developmental period in which they may no longer require the direction and intricacies of colouring in structured mandalas to help them remain focused and aware; it is possible that their more developed cognitive ability helps them create a mindfulness state from free colouring. Furthermore, males are no longer lagging behind in fine motor development during adolescence; they have essentially 'caught up' to their female counterparts and can experience the benefits associated with mandala colouring as well as free draw/colouring.

Anecdotally, the educators mentioned that mandala colouring clubs are held after school, and students practice mindfulness through a variety of different approaches during the year. Given the increased promotion of colouring mandalas in the media, it is possible that females may be more familiar with mandala colouring and engage in repeated practice, and the lack of 
Carsley, Effectiveness of mindfulness-based colouring for test anxiety in adolescents, 'School Psychology International' $(39,3)$ pp. 251-272. Copyright @ 2018 . DOI: 10.1177/0143034318773523.

novelty of the mandalas are resulting in the free colouring being more effective. In line with the DCS theory, participating in regular mindfulness activities can lead to skill acquisition and eventual development of expertise in this developmental period (Roeser \& Pinela, 2014; Roeser \& Zelazo, 2012), and perhaps adolescent females are now able to translate these skills from mindfulness activities to unstructured free colouring. It would be important to assess students' experiences with mandalas to determine if this can impact their response to the intervention. Another explanation — which builds on Carsley and Heath's (2018) finding — could be that personal preference might help determine who benefits from the activities. Although females demonstrated greater reductions in test anxiety following free drawing/colouring compared to males, decreases in test anxiety were still found for males in the free, as well as the mandala condition. These results suggest that the definition of an anti-stress or anti-anxiety activity might depend on students' preference and/or drawing ability. Given the lack of theoretical basis for these gender differences, and the mixed findings in previously conducted studies, replication of this study is required to assess the generalizability of the findings.

This study's second objective was to determine if pre-intervention state mindfulness mediates the relationship between participants' dispositional mindfulness and post-intervention state mindfulness, and whether pre-intervention test anxiety mediates the relationship between participants' dispositional mindfulness and post-intervention test anxiety. The relation between dispositional mindfulness and post-intervention outcomes were fully mediated by baseline measures, such that dispositional mindfulness' benefits for post-intervention state mindful- ness and test anxiety occurs through its effect on pre-intervention state mindfulness and test anxiety. In Carsley and Heath's (2018) study, participants with higher dispositional mindfulness demonstrated the highest possible levels of pre-intervention state mindfulness and were thus 
unable to report increases in state mindfulness post- intervention. The present study's findings suggest that dispositional mindfulness affects how participants respond to an intervention; if students report a general tendency to be mindful day-to-day, they are already entering the intervention with a certain baseline level of state mindfulness and associated lower test anxiety, and these baseline reports are determining to some degree the extent of changes in postintervention state mindfulness or test anxiety.

If students with high dispositional mindfulness and high pre-intervention state mindfulness or low pre-intervention test anxiety are not able to experience the benefits of the intervention, it is important to determine if there is a benefit to including mindfulness interventions for these students in educational settings. It would be interesting to examine if there is a way to assess 'deepening of' or 'enhancing' mindfulness states, regardless of individual dispositions. As a result, students who already maintain a general tendency to be mindful should in theory also be able to benefit from ongoing mindfulness interventions, although this requires further investigation. The current findings are promising and provide directions for future research; however, this study is not without limitations. First, given that both colouring activities were associated with decreases in test anxiety and increases in state mindfulness, the free condition may not be functioning as a control group. Future research would benefit from including a third non-colouring condition, in which participants engage in an alternative activity to compare changes in test anxiety and mindfulness to ensure the observed changes are not due to repeated measurement effects. Second, although participants were from public schools in the city, the schools in this sample have rigorous entrance requirements, thus the students are unusually high achieving relative to general school samples. Given this convenience sample and the original cross-sectional design developed by the researchers, further replication is required 
with a diverse group of students representing a variety of backgrounds. Third, given the increase in popularity of mindfulness colouring, some students' previous exposure to mandalas may have impacted their response to the activity; future research should include a question acknowledging students' previous experience with this activity. Finally, as mentioned in Carsley and Heath (2018), the field struggles with how to measure mindfulness. To remain consistent with the earlier work on pre-adolescent students, the state MAAS was employed as a measure of state mindfulness; however, due to the finding that reports of pre- intervention state mindfulness are explaining the relation between dispositional mindfulness and post-intervention state mindfulness, it would be helpful to find methods to assess 'enhancing' or 'deepening of' mindfulness for participants who maintain strong general mindfulness tendencies.

Despite these limitations, this research provides important information for educators and future research on mindfulness activities for test anxiety with adolescents. Both colouring activities demonstrate reductions in test anxiety and increases in mindfulness; therefore, it would be helpful for educators to implement these activities before a test. Although structured mandala colouring has been receiving attention in the media and throughout popular culture as a mindfulness-based activity for anxiety reduction, females reported greater decreases in test anxiety from free colouring. As such, it may not be necessary to focus on colouring in mandalas to experience benefits; adolescents, especially girls, may benefit equally, if not more, from free colouring, which is accessible and easy to implement. These activities may also be useful for students and teachers to implement during situations in which arousal or anxiety may be heightened in the classroom. Specifically, teachers could include mindfulness colouring as a class routine or calming moment when required. Given the high level of acceptability of this activity relative to other mindfulness practices, it can be easily tolerated in larger classrooms, in 
addition to individual sessions with school psychologists.

This activity is also feasible in different contexts where resources may be limited. Unlike complex mindfulness interventions that require training, materials, and greater time commitments, this research shows that simple mindfulness-based activities can be effective, accessible, and integrated into a variety of international contexts. Implementation of this mindfulness-based colouring activity requires no training, minimal resources and tools, and is feasible to implement beyond privileged school environments.

Given that pre-intervention state mindfulness and test anxiety explained relations between dispositional mindfulness and post-intervention state mindfulness and test anxiety, it is important for future studies to address how to enhance mindfulness for students with high dispositional mindfulness. If educators include mindfulness-based activities in their classrooms through a universal classroom-based approach, it is important to ensure all students are provided with opportunities to experience the associated benefits, regardless of individual differences. This study is the third study conducted in schools that demonstrates that free colouring is an equally effective mindfulness-based activity for test anxiety com- pared to structured mandalas in youth. Given the different findings in university studies that mandalas are considered to be more effective for anxiety compared to free colouring, it would be helpful to re-examine the effectiveness of these activities in university students with an additional non-colouring control group to determine if there is a difference between the three different developmental periods. 
Carsley, Effectiveness of mindfulness-based colouring for test anxiety in adolescents, 'School Psychology

International' $(39,3)$ pp. 251-272. Copyright @ 2018 . DOI: 10.1177/0143034318773523.

\section{References}

Arch, J. J., \& Craske, M. G. (2006). Mechanisms of mindfulness: Emotion regulation fol- lowing a focused breathing induction. Behavior Research and Therapy, 44, 1849-1858. doi: 10.1016/j.brat.2005.12.007

Arjunan, N. K., \& Joseph, J. (2016). Brief mindfulness meditation based stress reduction programme in controlling examination anxiety of secondary school students. The International Journal of Indian Psychology, 3(2), 95-103. doi:18.01.184/20160302

Beauchemin, J., Hutchins, T. L., \& Patterson, F. (2008). Mindfulness meditation may lessen anxiety, promote social skills, and improve academic performance among adolescents with learning disabilities. Complementary Health Practice Review, 13(34), 34-45. doi: $10.1177 / 1533210107311624$

Beckwith, P. (2014). Mindfulness and mandalas: Alternative therapeutic techniques for AOD adolescents. Capital University's Undergraduate Research Journal, n.a., 1-5.

Bennet, K., \& Dorjee, D. (2016). The impact of a mindfulness-based stress reduction course (MBSR) on well-being and academic attainment of sixth-form students. Mindfulness, 7, 105-114. doi: 10.1007/s12671-015-0430-7

Bishop, D., Bryant, K. S., Giles, S. M., Hansen, W. B., \& Dusenbury, L. (2006). Simplifying the delivery of a prevention program with web-based enhancements. The Journal of Primary Prevention, 27(4), 433-444. doi: 10.1007/s10935-006-0042-z

Bodhi, B. (2011). What does mindfulness really mean? A canonical perspective. Contemporary Buddhism, 12(1), 19-39. doi: 10.1080/ 14639947.2011.564813

Britton, W. B., Lepp, N. E., Niles, H., Rocha, R., Fisher, N. E., \& Gold, J. S. (2014). $\quad$ A randomized controlled pilot trial of classroom-based mindfulness meditation com- pared 
to an active control condition in sixth-grade children. Journal of School Psychology, 52, 263-278. doi: 10.1016/j.jsp.2014.03.002

Bradley, R., McCraty, R., Atkinson, M., Tomasino, D., Daugherty, D., \& Argueles, L. (2010). Emotion self-regulation, psychophysiological coherence, and test anxiety: Results from an experiment using electrophysiological measures. Applied Psychophysiology and Biofeedback, 35, 261-283. doi: 10.1007/s10484-010-9134-x

Brown, K. W., \& Ryan, R. M. (2003). The benefits of being present: Mindfulness and its role in psychological well-being. Journal of Personality and Social Psychology, 84(4), 822-848. doi: $0.1037 / 0022-3514.84 .4 .822$

Burke, C. A. (2010). Mindfulness-based approaches with children and adolescents: A preliminary review of current research in an emergent field. Journal of Child and Family Studies, 19(2), 133-144. doi: 10.1007/s10926-009-9282-x

Carsley, D., \& Heath, N. L. (2018). Evaluating the effectiveness of a mindfulness colouring activity for test anxiety in children. The Journal of Educational Research.

Carsley, D., Heath, N. L., \& Fajnerova, S. (2015). Effectiveness of a classroom mindfulness colouring activity for test anxiety in children. Journal of Applied School Psychology, 31(3), 239-255. doi: 10.1080/15377903.2015.1056925

Carsley, D., Khoury, B., \& Heath, N. L. (2017). Effectiveness of mindfulness interventions for mental health in school: A comprehensive meta-analysis. Mindfulness. doi: 10.1007/ s12671-017-0839-2 CASEL (2015). Collaborative for academic, social, and emotional learning. Retrieved from http://www.casel.org/social-and-emotional-learning/.

Chapell, M. S., Blanding, Z. B., Silverstein, M. E., Takahashi, M., Newman, B., Gubi, A., \& 
Carsley, Effectiveness of mindfulness-based colouring for test anxiety in adolescents, 'School Psychology

International' $(39,3)$ pp. 251-272. Copyright @ 2018 . DOI: 10.1177/0143034318773523.

McCann, N. (2005). Test anxiety and academic performance in undergraduate and graduate students. Journal of Educational Psychology, 97(2), 268-274. doi: 10.1037/ 0022-0663.97.2.268

Cunha, M., \& Paiva, M. J. (2012). Text anxiety in adolescents: The role of self-criticism and acceptance and mindfulness skills. The Spanish Journal of Psychology, 15(2), 533-543. doi: 10.5209/rev_SJOP.2012.v15.n2.38864

Curry, N. A., \& Kasser, T. (2005). Can coloring mandalas reduce anxiety? Art Therapy: Journal of the American Art Therapy Association, 22(2), 81-85. doi: 10.1080/ 07421656.2005 .10129441

Dalai Lama, \& Berzin, A. (1997). The Gelug/Kagyu tradition of Mahamudra. New York, NY: Snow Lion.

Eum, K., \& Rice, K. G. (2011). Test anxiety, perfectionism, goal orientation, and aca- demic performance. Anxiety, Stress, \& Coping, 24, 167-178. doi:10.1080/ 10615806.2010 .488723

Everson, H. T., Millsap, R. E., \& Rodriguez, C. M. (1991). Isolating gender differences in test anxiety: A confirmatory factor analysis of the Test Anxiety Inventory. Educational and Psychological Measurement, 51, 243-251. doi:10.1177/0013164491511024

Frank, J. L., Jennings, P. A., \& Greenberg, M. T. (2013). Mindfulness-based interventions in school settings: An introduction to the special issue. Research in Human Development, 10(3), 205-210. doi: 10.1080/15427609.2013.818480

Fridrici, M., \& Lohaus, A. (2009). Stress-prevention in secondary schools: Online-versus faceto-face-training. Health Education, 109, 299-313. doi: 10.1108/09654280910970884

Germer, C. K. (2005). Mindfulness: What is it? What does it matter? In C. K. Germer, R. 
D. Siegel, \& P. R. Fulton (Eds.), Mindfulness and psychotherapy (pp. 3-27). New York, NY: The Guilford Press.

Greco, L. A., Baer, R. A., \& Smith, G. T. (2011). Assessing mindfulness in children and adolescents: Development and validation of the child and adolescent mindfulness measure (CAMM). Psychological Assessment, 23(3), 606-614. doi: 10.1037/a0022819

Gregor, A. (2005). Examination anxiety: Live with it, control it or make it work for you?. School Psychology International, 26, 617-635. doi: 10.1177/0143034305060802

Hafenbrack, A. C., Kinias, Z., \& Barsade, S. G. (2014). Debiasing the mind through meditation: Mindfulness and the sunk-cost bias. Psychological Science, 25(2), 369-376. doi: $10.1177 / 0956797613503853$

Hanlon, H., Thatcher, R., \& Cline, M. (2000). Gender differences in the development of EEG coherence in normal children. Developmental Neuropsychology, 16(3), 479-506. doi: 10.1207/S15326942DN1603_27

Hembree, R. (1988). Correlates, causes, effects, and treatment of test anxiety. Review of Educational Research, 58, 47-77. doi: 10.2307/1170348

Henderson, P., Rosen, D., \& Mascaro, N. (2007). Empirical study on the healing nature of mandalas. Psychology of Aesthetics. Creativity, and the Arts, 1(3), 148-154. doi: $10.1037 / 1931-3896.1 .3 .148$

Johnson, C., Burke, C., Brinkman, S., \& Wade, T. (2016). Effectiveness of a school-based mindfulness program for transdiagnostic prevention in young adolescents. Behaviour Research and Therapy, 81, 1-11. doi: 10.1016/j.brat.2016.03.002

Kabat-Zinn, J. (2003). Mindfulness-based interventions in context: Past, present, and future. 
Carsley, Effectiveness of mindfulness-based colouring for test anxiety in adolescents, 'School Psychology

International' $(39,3)$ pp. 251-272. Copyright @ 2018 . DOI: 10.1177/0143034318773523.

Clinical Psychology: Science and Practice, 10(2), 144-156. doi: 10.1093/clipsy/bpg016

Kail, R. V., \& Cavanaugh, J. C. (2015). Human development: A life-span View (7th ed.). Boston, MA: Cengage Learning.

Kallapiran, K., Koo, S., Kirubakaran, R., \& Hancock, K. (2015). Review: Effectiveness of mindfulness in improving mental health symptoms of children and adolescents: A metaanalysis. Child and Adolescent Mental Health, 20(4), 182-194. doi: 10.1111/camh.12113

Kiken, L. G., Garland, E. L., Bluth, K., Palsson, O. S., \& Gaylord, S. A. (2015). From a state to a trait: Trajectories of state mindfulness in meditation during intervention predict changes in trait mindfulness. Personality and Individual Differences, 81, 41-46. doi: 10.1016/j.paid.2014.12.044

Kiken, L., \& Shook, N. (2011). Looking up: Mindfulness increases positive judgments and reduces negativity bias. Social Psychological \& Personality Science, 2, 425-431. doi: $10.1177 / 1948550610396585$

King, N. J., Mietz, A., Tinney, L., \& Ollendick, T. H. (1995). Psychopathology and cogni- tion in adolescents experiencing severe test anxiety. Journal of Clinical Child Psychology, 24, 49-54. doi:10.1207/s15374424jccp2401_6

Larson, H., Ramahi, M., Conn, S., Estes, L., \& Ghibellini, A. (2010). Reducing test anxiety among third grade students through the implementation of relaxation techniques. Journal of School Counseling, 8, 1-19.

LeBeau, R. T., Glenn, D., Liao, B., Wittchen, H., Beesdo-Baum, K., Ollendick, T., \& Craske, M. G. (2010). Specific phobia: A review of DSM-IV specific phobia and preliminary recommendations for DSM-V. Depression and Anxiety, 27, 148-167. doi:10.1002/da.20655

Lowe, P. A., Grumbein, M. J., \& Raad, J. M. (2011). Examination of the psychometric properties 
of the Test Anxiety Scale for Elementary Students (TAS-E) scores. Journal of Psychoeducational Assessment, 29, 503-514. doi:10.1177/0734282910395894

Lowe, P. A., \& Lee, S. W. (2008). Factor structure of the test anxiety inventory for children and adolescents (TAICA) scores across gender among students in elementary and sec- ondary school settings. Journal of Psychoeducational Assessment, 26, 231-246.

McDonald, A. S. (2001). The prevalence and effects of test anxiety in school children. Educational Psychology: An International Journal of Experimental Educational Psychology, 21(1), 89-101. doi: 10.1080/01443410020019867

Miller, J. J., Fletcher, K., \& Kabat-Zinn, J. (1995). Three-year follow up and clinical implications of a mindfulness meditation-based stress reduction intervention in the treatment of anxiety disorders. General Hospital Psychiatry, 17, 192-200. doi: 10.1016/01638343(95)00025-M

Napoli, M., Krech, P. R., \& Holley, L. C. (2005). Mindfulness training for elementary school students. Journal of Applied School Psychology, 21(1), 99-125. doi: 10.1300/ J370v21n01_05

Pekrun, R. (2000). A social-cognitive, control-value theory of achievement emotions. In J. Heckhausen (Ed.), Motivational psychology of human development: Developing motivation and motivating development (pp. 143-164). New York, NY: Elsevier.

Peleg, O. (2004). Differentiation and test anxiety in adolescents. Journal of Adolescence, 27, 645-662. doi: 10.1016/j.adolescence.2004.06.002

Preacher, K. J., \& Hayes, A. F. (2004). SPSS and SAS procedures for estimating indirect effects in simple mediation models. Behavior Research Methods, Instruments, and Computers, 36(4), 717-731. 
Putwain, D., Chamberlain, S., Daly, A. L., \& Sadreddini, S. (2014). Reducing test anxiety among school-aged adolescents: A field experiment. Educational Psychology in Practice, 30(4), 420-440. doi: 10.1080/02667363.2014.964392

Roeser, R. W. (2013). Mindfulness and human development: A commentary on the special issue. Research in Human Development, 10(3), 273-283. doi: 10.1080/15427609. 2013.818490

Roeser, R. W., \& Pinela, C. (2014). Mindfulness and compassion training in adolescence: A developmental contemplative science perspective. New Directions for Youth Development, 142, 9-30. doi: 10.1002/yd.20094

Roeser, R. W., \& Zelazo, P. D. (2012). Contemplative science, education and child development: Introduction to the special section. Child Development Perspectives, 6(2), 143145. doi: 10.1111/j.1750-8606.2012.00242.x

Segool, N., Carlson, J., Goforth, A., von der Embse, N., \& Barterian, J. (2013). Heightened test anxiety among young children: Elementary school students' anxious responses to highstakes testing. Psychology in the Schools, 50, 489-499. doi:10.1002/pits.21689

Shapiro, S. L., Oman, D., Thoresen, C. E., Plante, T. G., \& Flinders, T. (2008). Cultivating mindfulness: Effects on well-being. Journal of Clinical Psychology, 64(7), 840-862. doi: 10.1002/jclp.20491

Sowell, E. R., Thompson, P. M., Holmes, C. J., Jernigan, T. L., \& Toga, A. W. (1999). In vivo evidence for post-adolescent brain maturation in frontal and striatal regions. Nature Neuroscience, 2(10), 859-861. doi: 10.1038/13154

Spielberger, C. D. (1989). State-Trait Anxiety Inventory: A comprehensive bibliography. Palo Alto, CA: Consulting Psychologists Press.

Spielberger, C. D., Gorsuch, R. L., Lushene, R., Vagg, P. R., \& Jacobs, G. A. (1983). 
Manual for the State-Trait Anxiety Inventory. Palo Alto, CA: Consulting Psychologists Press.

Swanson, S., \& Howell, C. (1996). Test anxiety in adolescents with learning disabilities and behavior disorders. Exceptional Children, 62, 389-397. doi:

10.1177/001440299606200501 Tabachnick, B. G., \& Fidell, L. S. (2007). Using multivariate statistics, 5th edn. Boston, MA: Pearson Education Inc.

Tan, L. B. B. (2016). A critical review of adolescent mindfulness-based programmes. Clinical Child Psychology and Psychiatry, 21(2), 193-207. doi: 10.1177/1359104515577486

Tobias, S. (1979). Anxiety research in educational psychology. Journal of Educational Psychology, 71, 573-582.

Van der Vennet, R., \& Serice, S. (2012). Can coloring mandalas reduce anxiety? A replication study. Art Therapy: Journal of the American Art Therapy Association, 29(2), 87-92. doi: $10.1080 / 07421656.2012 .680047$

von der Embse, N., \& Hasson, R. (2012). Test anxiety and high-stakes tests: Implications for educators. Preventing School Failure, 56(3), 180-187. doi:

10.1080/1045988X.2011.633285

Weems, C., Taylor, L., Costa, N., Marks, A., Romano, D., Verrett, S., \& Brown, D. M. (2009). Effect of a school-based test anxiety intervention in ethnic minority youth exposed to Hurricane Katrina. Journal of Applied Developmental Psychology, 30, 218-226. doi: 10.1016/j.appdev.2008.11.005

Whitaker Sena, J. D., Lowe, P. A., \& Lee, S. W. (2007). Significant predictors of test anxiety among students with and without learning disabilities. Journal of Learning Disabilities, 40(4), 360-376. doi: 10.1177/00222194070400040601 
Wren, D. G., \& Benson, J. (2004). Measuring test anxiety in children: Scale development and internal construct validation. Anxiety, Stress and Coping, 17(3), 227-240. doi: 10.1080/ 10615800412331292606

Yahav, R., \& Cohen, M. (2008). Evaluation of a cognitive-behavioral intervention for adolescents. International Journal of Stress Management, 15, 173-188.

Zenner, C., Herrnleben-Kurz, S., \& Walach, H. (2015). Mindfulness-based interventions in schools - a systematic review and meta-analysis. Frontiers in Psychology, 5(603). doi: 10.3389/fpsyg.2014.00603

Zoogman, S., Goldberg, S. B., Hoyt, W. T., \& Miller, L. (2014). Mindfulness interventions with youth: A meta-analysis. Mindfulness. doi: 10.1007/s12671-013-0260-4 


\section{Tables and Figures}

Table 1. Demographic information and pre-intervention test anxiety and state mindfulness scores across participant group.

\begin{tabular}{llll}
\hline Variable & Mandala group & Free group & Significance test \\
\hline Gender, \% female & $54.6 \%$ & $58.3 \%$ & $\mathrm{x}^{2}(1)=3.24, p=0.072$ \\
Age, $M$ (SD) & $13.46(.50)$ & $13.52(.50)$ & $t(191)=0.79, p=0.68$ \\
Test anxiety (pre), M (SD) & $37.04(10.74)$ & $37.34(9.79)$ & $t(191)=0.20, p=0.84$ \\
State Mindfulness (pre), M (SD) & $4.38(1.18)$ & $4.33(1.09)$ & $\mathrm{t}(191)=0.26, \mathrm{p}=0.80$
\end{tabular}

Table 2. Means (and Standard Deviations) for test anxiety and state mindfulness levels in the mandala and free colouring groups.

\begin{tabular}{llllll}
\hline & & Test anxiety & Test anxiety & State mindfulness & State mindfulness \\
& & $($ Pre $)$ & $($ Post $)$ & $($ Pre $)$ & $($ Post $)$ \\
\cline { 3 - 6 } Group & $\mathrm{N}$ & $\mathrm{M}(\mathrm{SD})$ & $\mathrm{M}(\mathrm{SD})$ & $\mathrm{M}(\mathrm{SD})$ & $\mathrm{M}(\mathrm{SD})$ \\
\hline Mandala & 97 & $37.04(10.74)$ & $31.29(8.68)$ & $4.38(1.18)$ & $4.74(1.19)$ \\
Free & 96 & $37.34(9.79)$ & $31.81(8.43)$ & $4.33(1.09)$ & $4.75(1.11)$ \\
\hline
\end{tabular}


Carsley, Effectiveness of mindfulness-based colouring for test anxiety in adolescents, 'School Psychology International' $(39,3)$ pp. 251-272. Copyright @ 2018 . DOI: 10.1177/0143034318773523.

Table 3. Correlations between dispositional mindfulness, pre-intervention state mindfulness, and post-intervention state mindfulness.

\begin{tabular}{lllll}
\hline & & 1 & 2 & 3 \\
\hline Dispositional mindfulness & $\mathrm{r}$ & 1 & & \\
Pre-intervention state mindfulness & $\mathrm{r}$ & $0.39^{*}$ & 1 & \\
& $\mathrm{n}$ & 193 & & \\
3. Post-intervention state mindfulness & $\mathrm{r}$ & $0.29^{*}$ & $0.74^{*}$ & 1 \\
& $\mathrm{n}$ & 193 & 193 & \\
\hline *p $<.01$. & & & &
\end{tabular}

Table 4. Correlations between dispositional mindfulness, pre-intervention test anxiety, and postintervention test anxiety.

\begin{tabular}{lcccc}
\hline & & 1 & 2 & 3 \\
\hline 1. Dispositional mindfulness & $\mathrm{r}$ & 1 & \\
2. Pre-intervention test anxiety & $\mathrm{r}$ & $-.50^{*}$ & 1 & \\
3. Post-intervention test anxiety & $\mathrm{n}$ & 193 & $.65^{*}$ & 1 \\
& $\mathrm{r}$ & $-.39 *$ & 193 \\
\hline
\end{tabular}




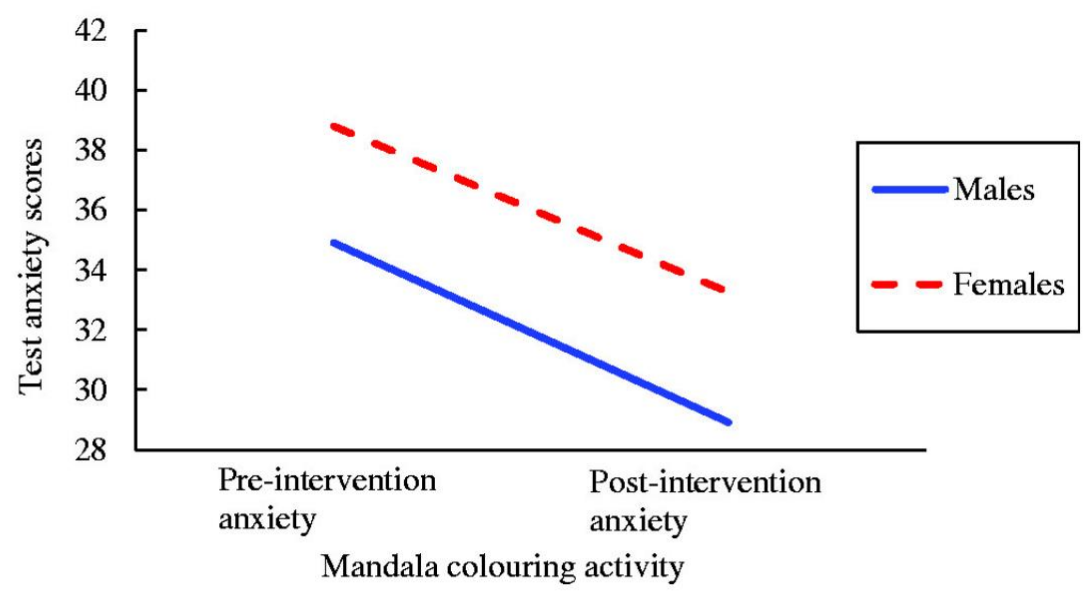

Figure 1.1. Pre- to post-intervention test anxiety scores in the mandala condition.

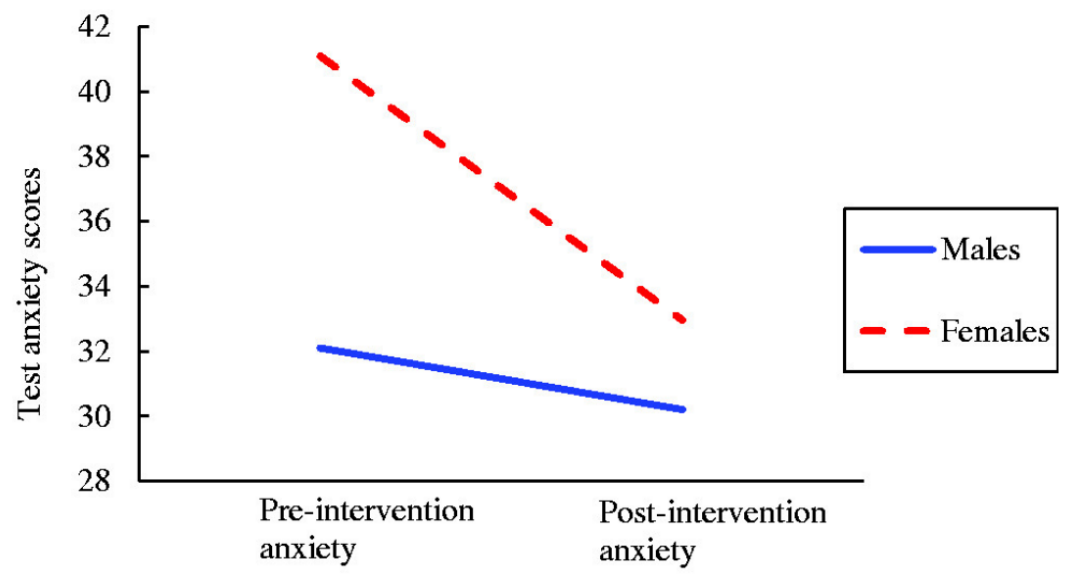

Free colouring activity

Figure 1.2. Pre- to post-intervention test anxiety scores in the free condition. 
Carsley, Effectiveness of mindfulness-based colouring for test anxiety in adolescents, 'School Psychology International' $(39,3)$ pp. 251-272. Copyright @ 2018 . DOI: 10.1177/0143034318773523.

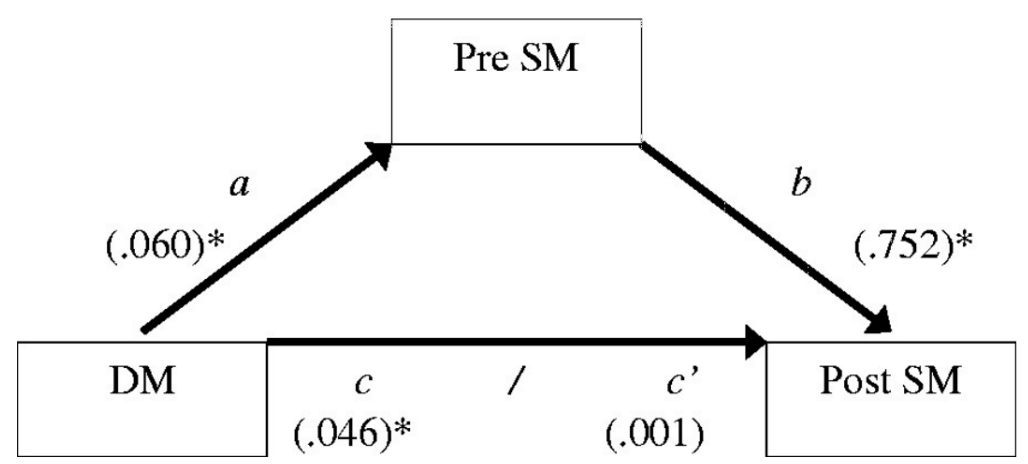

Figure 2.1. The mediating effect of pre-intervention state mindfulness in the association between dispositional mindfulness and post-intervention state mindfulness.

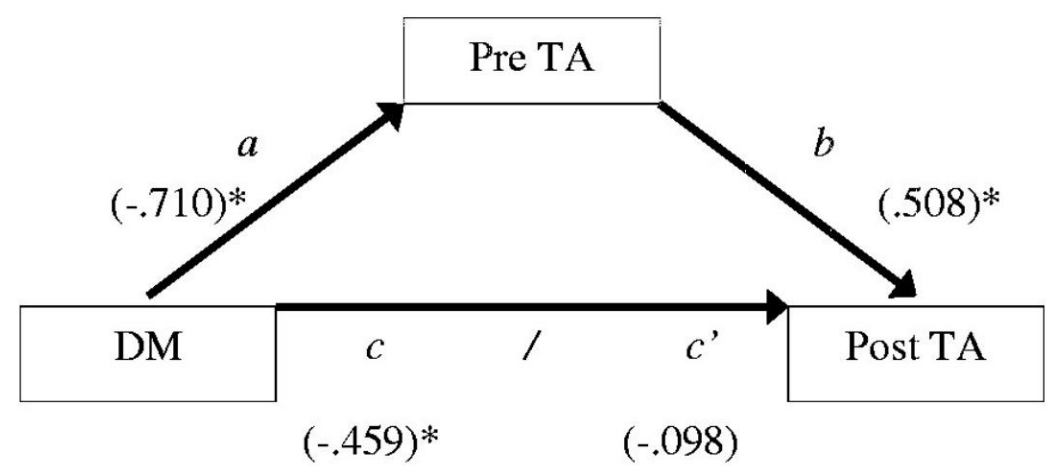

Figure 2.2. The mediating effect of pre-intervention test anxiety in the association between dispositional mindfulness and post-intervention test anxiety. Notes: Standardized path coefficients are shown in parentheses. $\mathrm{DM}=$ dispositional mindfulness; Pre $\mathrm{SM}=$ preintervention state mindfulness; Post $\mathrm{SM}=$ post-intervention state mindfulness; Pre TA=preintervention test anxiety; Post $\mathrm{TA}=$ post-intervention test anxiety. $\mathrm{N}=193 .{ }^{*} \mathrm{p}<.001$. 